\title{
RUNNING SAFETY TIPS FOR HUMANS
}

\author{
Exercise caution.
}

\section{BY MARISSA LINGEN}

I $n$ the early days after the Vitclemp Arrival Event, many humans found their exercise routines altered by social upheaval. Now that we have settled into the Glorious Vitclemp Protectorate, humans are starting to return to their former habits. Here are some tips to keep you safe as you restart your human running routine.

1. Never permit your sweat to touch the air. Of course almost all Vitclemps can tell the difference between humanity and other mammals, which are all their rightful prey species under the treaty settlement. But be responsible! Don't tempt them with your mammalian-scented juices! Although Kratos was primarily known as a shoe company before the Arrival, they have also manufactured clothing for quite some time, and their sweatwicking garments will help you to have a safe run.

Be sure to choose a headpiece with adequate nose and forehead coverage. This 'T-zone' of mammalian cooling goop is often neglected by casual runners.

\section{Do not run near any bodies of water.} Although, of course, the vast majority of our Vitclemp Protectors are able to tell humans from other prey animals, the youngest Vitclemp have the most difficulty controlling their natural urges, and they, of course, spend the most time submerged in the wetlands so abundant on this planet, making it clear that it was ideally designed for their comfort. If you startle a sleeping adolescent Vitclemp awake, their instincts will rouse faster than their training. Be safe and stay away from all water. This includes lakes, ponds, streams, rivers, marshes, oceans and sloughs.

3. Don't drag your toes. Try not to heelstrike. You can really mess your feet up that way, and there aren't as many podiatrists as there used to be. If it was an organ the Vitclemp shared, it would be different. Try for good form to protect your feet.

\section{Report your route plan in advance.}

$\rightarrow$ NATURE.COM

Follow Futures:

@ @NatureFutures

$f$ go.nature.com $/ \mathrm{mtoodm}$
If you tell both the Central Commander at your local Protectorate station and a friend or family member, it will increase the odds that someone will notice you are missing before an unfortunately misguided Vitclemp has time to engulf you completely. Even if you do get engulfed, this will give the Protectorate and your loved ones a chance to track down your inorganic belongings, which many humans find a comfort in times of loss. Having your sister's watch, your college friend's ruptured

in a prey-species misunderstanding with a Vitclemp can appeal to the other Vitclemp to summon, admonish or even intervene with their unfortunate peer who has temporarily become addled, in parts of the emotional and auditory spectrum that human voices simply cannot reach. A running route that went directly around the local Protectorate station and barracks might well be the safest possible choice.

If this is not available, other humans can at least bear witness and report back to human kin and affine groups about the demise of their fellow, gather inorganic possessions, etc. as above. Areas well-populated with Vitclemp are the safest, with other humans the second-safest.

Under no circumstances should humans enter any woods, meadows or other natural surroundings for their running exercise. Those habitats are filled with prey species and it would be entirely irresponsible to confuse

Vitclemp in this fashion. Humans wishing to enjoy the natural beauty of our shared planet should register for tours in sealed all-terrain vehicles.

7. Wear reflective clothing. Very few acceptable prey species have shiny reflective spots, including none of the ones on Earth, although scientists are now studying evolving coat patterns in Alces alces, the North American moose, since the time of the Arrival.

5. Carry pepper spray. Pepper is a disgusting human condiment. If a Vitclemp makes a regrettable species misidentification, simply spray yourself with pepper spray. Aim for the head and torso; any limbs they have already engulfed are probably a lost cause, and there are far better prosthetics for legs than for heads! [smiley]

Because pepper plants are not grown nearly as widely as they were before the Protectorate, pepper spray may be out of the reach of your paltry human budget. Consider making a homemade allspice spray from a solution of allspice, water and ume vinegar. Although this flavour combination is not nearly so noxious as pepper, its pungent taste may shock a Vitclemp into disengulfing at least part of a human and rethinking what species they have.

There are no recorded cases of this working, but it seems unlikely to hurt.

6. Stay near settlements. Although it's counter-intuitive that more Vitclemp would mean less risk for a human runner, a human
8. Follow rules of precedence on the roads. All humans are aware that Vitclemp take road priority. Many are unaware that mechanical autonomous vehicles, MAVs, also take precedence. Diving into a ditch is acceptable to clear the road for those with precedence, although again, check your route in advance to make sure that none of the ditches fills with water. This protocol should be familiar, as automobiles had precedence on the road over human pedestrians and self-powered vehicles before the Arrival.

Human exercise customs may still be indulged and enjoyed in the glorious days of our Protectorate! Exercise common sense and understanding with our Vitclemp friends for a fun — and safe - run.

Marissa Lingen has published more than 100 short stories in venues such as Analog, Lightspeed and Tor.com. 